\title{
Management of acute type A intramural hematoma: upfront surgery or individualized approach? A retrospective analysis and meta-analysis
}

\author{
Simon C. Y. Chow ${ }^{1}$, Randolph H. L. Wong ${ }^{1}$, Ishan Lakhani ${ }^{2}$, Michelle V. Wong ${ }^{2}$, Gary Tse ${ }^{2}$, \\ Peter S. Y. Yu ${ }^{1}$, Jacky Y. K. Ho ${ }^{1}$, Takuya Fujikawa ${ }^{1}$, Malcolm J. Underwood ${ }^{1}$ \\ ${ }^{1}$ Division of Cardiothoracic Surgery, Department of Surgery, The Chinese University of Hong Kong, Prince of Wales Hospital, 30-32 Ngan Shing \\ Street, Shatin, New Territories, Hong Kong SAR, China; ${ }^{2} \mathrm{Li}$ Ka Shing Institute of Health Sciences, Faculty of Medicine, The Chinese University of \\ Hong Kong, Hong Kong SAR, China \\ Contributions: (I) Conception and design: SCY Chow; (II) Administrative support: RHL Wong, MJ Underwood; (III) Provision of study materials or \\ patients: All authors; (IV) Collection and assembly of data: All authors; (V) Data analysis and interpretation: All authors; (VI) Manuscript writing: All \\ authors; (VII) Final approval of manuscript: All authors. \\ Correspondence to: Simon C. Y. Chow, FRCS. Malcolm John Underwood, Division of Cardiothoracic Surgery, Department of Surgery. The Chinese \\ University of Hong Kong, Prince of Wales Hospital, 30-32 Ngan Shing Street, Shatin, New Territories, Hong Kong SAR, China. \\ Email: wwjdsimon@gmail.com.
}

Background: Management of acute type A intramural hematoma (IMH) is a controversial topic. In our study, we aim to analyze the survival outcomes in local patients with acute type A IMH and a meta-analysis on survival in type A IMH treated medically versus surgically was performed.

Methods: From 2014 to 2019, 65 patients with acute type A IMH were selected for analysis. Primary outcome of interest was 1 year all cause survival. The rate of aortic-related events in the medical group was evaluated. PubMed and Embase were searched for meta-analysis.

Results: The mean age of our cohort was $61.7 \pm 9.7$ years. Of the 65 patients, $40 \%$ had emergency operation. Overall 1-year survival was $96.9 \%$. The 1 -year survival was $94.9 \%$ for the medical group. $46.2 \%$ of the medical group required aortic intervention at a mean duration of $191 \pm 168$ days. Maximal aortic diameter $(\mathrm{MAD}) \geq 45 \mathrm{~mm}$ was predictive of aortic-related events in the medical group (OR: 7.0; 95\% CI, 1.7-29.4; $\mathrm{P}=0.008)$. For the meta-analysis, 21 studies were identified, and 900 patients were included. Emergent surgery was associated with improved survival in type A IMH (OR: 0.76; 95\% CI, 0.29-1.97, $\left.\mathrm{P}=0.58 ; \mathrm{I}^{2}=27 \%\right)$.

Conclusions: The 1-year survival after type A IMH was promising, regardless of approach. The conservative-first approach was found to be safe \& feasible, and upfront surgery remained the management of choice in general. Patients with $\mathrm{MAD} \geq 45 \mathrm{~mm}$ was associated with subsequent aortic intervention in the medical-first group.

Keywords: Aorta; acute aortic dissection; ascending aorta; medical therapy; surgery

Submitted Sep 01, 2019. Accepted for publication Dec 13, 2019.

doi: $10.21037 /$ jtd.2019.12.109

View this article at: http://dx.doi.org/10.21037/jtd.2019.12.109

(c) Journal of Thoracic Disease. All rights reserved. 


\section{Introduction}

Type A intramural hematoma (IMH) represents around $5-23 \%$ of all acute aortic syndromes (1). Type A IMH is conventionally managed similarly to classical aortic dissection, especially in the West. However, compared to classical aortic dissection, the understanding about the pathogenesis of IMH is less certain and studies have shown type A IMH could run a different natural course, indeed a more benign one. By definition, IMH differs from classical dissection in that there is no flow in the false lumen and it is postulated that the etiology of IMH originates from ruptured vasa vasorum or atherosclerotic plaques in the aortic wall rather than intimal tears (2). Krukenberg first described IMH in 1920 as "dissection without a tear" (3). The natural history of IMH was reported to be different from classical dissection in that the rates of complications such as malperfusion and aortic regurgitation were lower. Nonetheless, reports from the West recommended early surgery for type A IMH as medical therapy was found to be associated with worse survival with high rates of rupture and tamponade (4-6). Findings in the Asian population have offered a different perspective and shown favorable survival outcomes with the medical-first approach, and has underlined the role of medical therapy in patients with type A IMH with no complications $(7,8)$. To date, there are no high quality comparative studies comparing surgery versus medical therapy. Nonetheless, it is worth noting that patients with type A IMH are generally older and have more comorbidities than patients with classical dissection and inevitably this also puts these patients at a higher risk of mortality from emergency aortic surgery. In this context, it would be interesting to explore another perspective on management of acute type A IMH. In our study, we aim to achieve two objectives. Firstly, through reviewing our own experience on managing type A IMH, we sought to evaluate the survival outcomes of patients treated with upfront surgery and initial medical therapy. Secondly, through a systematic review and literature based meta-analysis, we examined the relationship of survival in type A IMH between surgical and medical management.

\section{Methods}

Between January 2014 and June 2019, 69 patients were admitted for acute type A IMH in the Prince of Wales Hospital, Hong Kong. This made up around $20 \%$ of all admission for acute aortic syndrome. These patients were consecutively selected from our local aortic registry and relevant data were retrospectively extracted from patient records for analysis. All patient data were extracted from the comprehensive Dendrite local Clinical database system in Hong Kong. This cardiac surgical local registry was approved by the Hong Kong Hospital Authority and the Government of Hong Kong SAR to allow collection, analysis, reporting and outcome tracking of patient data since its introduction in 2007. No informed consents from patients were sought for this retrospective analysis as there were no identifiers in this manuscript that could disclose individual patient confidentiality. Patient anonymity was preserved in this study. Inclusion criteria for analysis included (I) age $\geq 18$; (II) presence of type A IMH defined as presence of high-attenuation crescent sign on non-contrast CT in the ascending aorta proximal to the brachiocephalic artery, with lack of contrast enhancement in the false lumen during arterial and delayed phase; (III) fitness for open surgery or endovascular intervention. Patients who had classical aortic dissection with free-flowing contrast in the false lumen were excluded from analysis, as life-saving surgery was required for all patients unless unfit. 4 Patients were considered unfit for any intervention and were excluded from analysis; hence 65 patients were included for analysis. Of the 4 patients, 2 patients were excluded due to frailty, 1 patient developed multi-organ failure and 1 patient was suspected to have aortobronchial fistula but was considered at prohibitive risk for surgery due to advanced age and was in extremis. Presence of penetrating aortic ulcers (PAU) was defined as areas of ulceration extending into the IMH, and their locations were recorded. The thickness of IMH was measured in the ascending aorta. The maximal aortic diameter (MAD) of the ascending aorta was measured as the maximum wall-to-wall diameter of the aorta proximal to the take-off of the brachiocephalic artery including the IMH on axial computed tomography scan (Figure S1). All patient data had been secured and kept confidential.

The primary outcome of interest was 1 -year all cause survival and 1-year rates of aortic-related complications requiring subsequent aortic intervention. Aortic related events were defined as aortic complications that necessitated the patient to have open or endovascular aortic intervention. They included chest or back pain despite adequate systolic blood pressure control of less than $120 \mathrm{mmHg}$, increase in size of MAD around $\geq 5 \mathrm{~mm}$ within 6 months, increasing thickness of IMH, increasing pericardial effusion or tamponade, PAU at ascending or arch of aorta, rupture 
(frank or concealed) and fistulation.

Procedural records were retrospectively analyzed, and operative factors were taken into account. The timing of operation was documented, and the nature of procedure was analyzed. The 30 -day procedural mortality rates were accounted for and analyzed. Medical therapy included admission to a high dependency unit with intensive blood pressure monitoring with an intra-arterial line in the patient's radial artery. Optimal blood pressure target was systolic blood pressure $\leq 120 \mathrm{mmHg}$. To date, there is no robust evidence suggesting the best blood pressure target for dissections, but most guidelines suggest a SBP target of $100-120 \mathrm{mmHg}$. IV antihypertensives were given for blood pressure control and patients had daily bedside ultrasound monitoring for new occurrence of pericardial effusion and aortic regurgitation. Most patients who remained stable had a repeat $\mathrm{CT}$ aortogram at 1 week after admission.

The meta-analysis was performed according to the Preferred Reporting Items for Systematic Reviews and Meta-Analyses (PRISMA) statement. Pubmed and Embase were searched for studies that examined the relationship between medical and surgical therapy and early mortality in patients with Type A IMH. The following search terms were used: (((intramural hematoma) AND ((medical therapy) OR (surgical) OR (endovascular) OR (stent) OR (graft) OR (aortic dissection))). The search period was from the year 1996 onwards for PubMed, and the year 1910 onwards for Embase without language restrictions. The following inclusion criteria were used: (I) The study was a prospective or retrospective, randomized or nonrandomized comparative study in humans and (II) all-cause mortality were reported or could be calculated from the published data. The Newcastle-Ottawa Quality Assessment Scale (NOS) was used for quality assessment of the included studies. The NOS point score system evaluated the categories of study participant selection, comparability of the results, and quality of the outcomes. The following characteristics were assessed: (I) representativeness of the respective cohorts; (II) demonstration that outcome of interest was not present at the start of study; (III) comparability of cohorts based on study design or analysis; (IV) assessment of outcomes; (V) follow-up periods that were sufficiently long for outcomes to occur; and (VI) adequacy of follow-up of cohorts. This scale ranged from zero to nine stars, which indicated that studies were graded as poor quality if the score was $<5$, fair if the score was 5 to 7 , and good if the score was $>8$.

\section{Statistical analysis}

The perioperative 1-year data from our own cohort was analysed using IBM SPSS statistics ${ }^{\circledR}$ Version 25 . Continuous variables were presented as mean \pm standard deviations. Categorical variables were expressed as frequencies and percentages. Kaplan-Meier analysis was performed for survival analysis. Differences between means were calculated with student $t$ test, and differences between frequencies were compared with Chi-square test, with $\mathrm{P}$ values $\leq 0.05$ considered statistically significant.

Univariate analysis of perioperative factors predictive of survival were analyzed with the log-rank test. Significant predictors of mortality had $\mathrm{P}$ values $\leq 0.05$. Analysis of association between categorical or continuous variables and outcomes of interest were performed with binary logistic regression studies. If more than one factor was found to be associated with an outcome, multivariate analysis was performed to adjust for confounders.

For the meta-analysis, all abstracts were retrieved as complete manuscripts and assessed against the inclusion criteria. The data extracted included study design, follow up duration, endpoints, quality score and characteristics of the studied population. Two reviewers (IS and MVW) reviewed each included study independently. Disagreements were resolved by adjudication with input from a third reviewer (SC). Statistical analysis was performed using Review Manager (RevMan) (Computer program) Version 5.3. (Copenhagen: The Nordic Cochrane Centre The Cochrane Collaboration, 2014). Heterogeneity between studies was determined using Cochran's Q value, the weighted sum of squared differences between individual study effects and the pooled effect across studies, and the $\mathrm{I}^{2}$ statistic determined from the standard chi-square test, which describes the proportion of total variance-explained heterogeneity. $\mathrm{I}^{2}>50 \%$ was considered to reflect significant statistical heterogeneity. A fixed effects model was used if $\mathrm{I}^{2}<50 \%$, otherwise the random-effects model using the inverse variance heterogeneity method was used. To identify the source of the heterogeneity, sensitivity analysis using the leave-one-out method was performed.

\section{Results}

\section{Patient demographics}

Table 1 displays the baseline characteristics of the studied population. The mean age of the cohort was $61.7 \pm 9.7$ years, 
Table 1 Baseline demographics of local cohort

\begin{tabular}{lc}
\hline Baseline demographics ( $\mathrm{n}=65)$ & $\begin{array}{c}\text { Mean } \pm \text { SD or } \\
\text { frequencies }(\%)\end{array}$ \\
\hline Age (years) & $61.7 \pm 9.7$ \\
Male & $44(67.7)$ \\
Smoker & $30(46.1)$ \\
HT & $49(75.4)$ \\
DM & $5(7.7)$ \\
Dialysis dependent chronic renal failure & $2(2.8)$ \\
Maximal aortic diameter (mm) & $47.3 \pm 7.1$ \\
Intramural hematoma thickness in ascending & $13.5 \pm 7.8$ \\
aorta (mm) & \\
Penetrating aortic ulcer/ulcer like projection & $29(44.6)$ \\
Penetrating aortic ulcer in arch/descending & $54(83.5)$ \\
aorta & \\
Penetrating aortic ulcer below diaphragm & $8(12.5)$ \\
Penetrating ulcer in ascending aorta & $3(4.6)$ \\
Aortic regurgitation/tamponade/malperfusion & $2(3.0)$ \\
on presentation & \\
Operation within 24 hours & $26(40.0)$ \\
Operation within 1 week & $28(43.1)$ \\
Operation within 1 month & $38(58.4)$ \\
\hline & \\
\hline
\end{tabular}

$67.7 \%$ of the patient was of male gender, $46.1 \%$ were smokers and $75 \%$ had history of hypertension. All cases were emergency admissions, and $3 \%$ of cases had hemodynamic instability with cardiac tamponade and acute aortic regurgitation. Overall, the mean MAD was $47.3 \pm 7.1$ $\mathrm{mm}$ and the mean ascending aortic IMH thickness was $13.5 \pm 7.8 \mathrm{~mm} .44 .6 \%$ patients had penetrating aortic ulcer (PAU), and $83.5 \%$ had a PAU in the arch or descending thoracic aorta. $40.0 \%$ of the population had operation performed within 24 hours of admission, while $43.1 \%$ had operation done within 1 week. Overall, $58.4 \%$ of patients had operation done within 1 month.

\section{Survival}

Table 2 displays the results concerning survival. The overall 30-day survival was $98.2 \%$ and the 1 year all cause survival rate was $96.9 \%$ (Figure S2). None of the patients with emergency operation done within 24 hours died. $88 \%$ of all emergency operations were hemiarch or ascending aortic replacements. For patients initially treated with antiimpulse therapy, the 1 year all cause survival rate was $94.9 \%$ (Figure 1). Amongst those treated medically initially, 46.2\% developed aortic-related events and indications which required subsequent aortic interventions. The mean time to subsequent aortic intervention was $191 \pm 168$ days. $10.3 \%$ of aortic related events were due to persistent pain despite medical therapy, $38.5 \%$ of patients had increasing MAD and $17.9 \%$ had increasing thickness of IMH. $17.9 \%$ had new PAU noted at the ascending aorta or arch. Amongst the aortic procedures performed in the patients treated with medical therapy initially, $50 \%$ went on to have a hemiarch replacement, $28 \%$ had total arch replacement and elephant trunk procedure, $17 \%$ had thoracic endovascular aortic repair (TEVAR) with zone 2 landing and $5 \%$ had descending aortic replacement (Table S1). $36 \%$ of patients initially treated medically had resolution of IMH on conservative management alone. Among the 21 patients who were purely medically treated, 14/21 had resolution of IMH on subsequent CT scans. Comparison between baseline demographics of the patients with or without emergency operation revealed patients with operation done within 24 hours had a thicker IMH in the ascending aorta $(18.7 \pm 6.8$ vs. $10.1 \pm 5.0 \mathrm{~mm} ; \mathrm{P}<0.001)$. There was no difference in the MAD. It was more likely to identify a PAU on the presenting CT scan for patients who did not have emergency operation $(19.2 \%$ vs. $61.5 \% ; \mathrm{P}=0.001)$.

\section{Risk factor analysis}

No analysed risk factors were associated with 1 year all cause survival. The mortality event rates were too low for both upfront surgery or medical-first groups to make a meaningful risk factor analysis relating to all cause survival, but MAD was associated with a higher risk of aortic-related complications at 1 year in patients initially treated medically (OR: 1.41; 95\% CI, 1.10-1.81; $\mathrm{P}=0.007)$. MAD $\geq 45 \mathrm{~mm}$ was associated with higher odds for aortic interventions at 1 year for the group treated medically initially (OR: 7.0; 95\% CI, 1.7-29.4; $\mathrm{P}=0.007$ ) (Table S2). The rate of subsequent aortic intervention at 1 year was $64.6 \%$ in patients with $\mathrm{MAD} \geq 45 \mathrm{~mm}$ versus $24.5 \%$ in those with MAD $<45 \mathrm{~mm}(\mathrm{P}=0.007)$ (Figure 2). MAD $<45 \mathrm{~mm}$ was also associated with spontaneous resolution of IMH (OR: 19; 95\% CI, 3.29-110.0; $\mathrm{P}=0.001)$. 
Table 2 Survival data of local cohort

\begin{tabular}{|c|c|}
\hline Survival analysis & Mean \pm SD or frequencies (\%) \\
\hline Overall 1-year survival & $63 / 65(96.9)$ \\
\hline Emergency operation 1-year mortality [operated type A intramural hematoma (IMH) within 24 hours] & $0 / 26(0)$ \\
\hline Patients with no operation done within 24 hours & $39 / 65(60.0)$ \\
\hline $\begin{array}{l}\text { Rate of subsequent aortic-related complications requiring intervention in patients who did not have } \\
\text { emergency operation }\end{array}$ & $18 / 39(46.2)$ \\
\hline Mean time to subsequent aortic intervention (days) & $191 \pm 168$ \\
\hline Resolution of type A IMH in purely medically treated patients & $14 / 21(66.7)$ \\
\hline Increase in size & $15 / 39(38.5)$ \\
\hline Increasing thickness of IMH & $7 / 39(17.9)$ \\
\hline Increasing hemopericardium & $4 / 39(10.3)$ \\
\hline New PAU at ascending/arch & 7/39 (17.9) \\
\hline Rupture/fistulation & 2/39 (5.1) \\
\hline
\end{tabular}

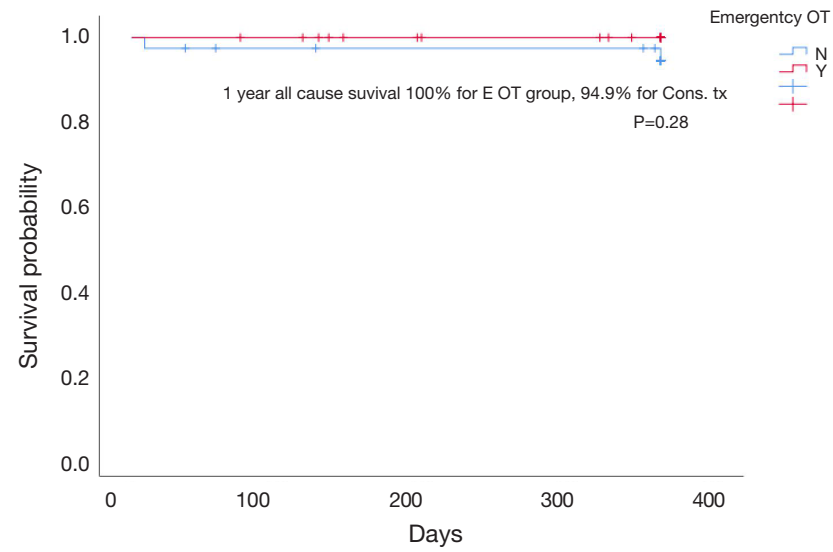

Figure 1 Kaplan Meier Analysis of 1 year all cause survival in patients with acute type A intramural hematoma (IMH): emergently operated \& initial conservative treatment.

\section{Meta-analysis}

A flow diagram of the study identification and selection process is shown in Figure 3. A total of 1,395 and 943 entries were retrieved from PubMed and Embase, respectively, of which 21 studies met the inclusion criteria. Flow details

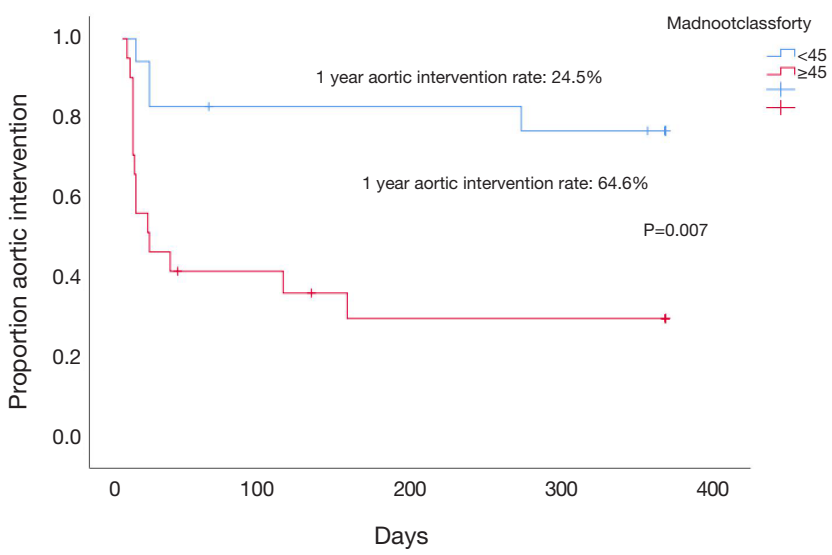

Figure 2 Kaplan Meier analysis of 1-year aortic intervention in patients with initial conservative treatment and maximal aortic diameter (MAD) $45 \mathrm{~mm}$ or above $\&<45 \mathrm{~mm}$.

of the NOS quality assessment and characteristics of these studies are shown in the supplementary information (Table S3). In total, 900 patients were included for analysis. All 21 studies examined the relationship between initial medical therapy versus surgery and all-cause mortality, of 


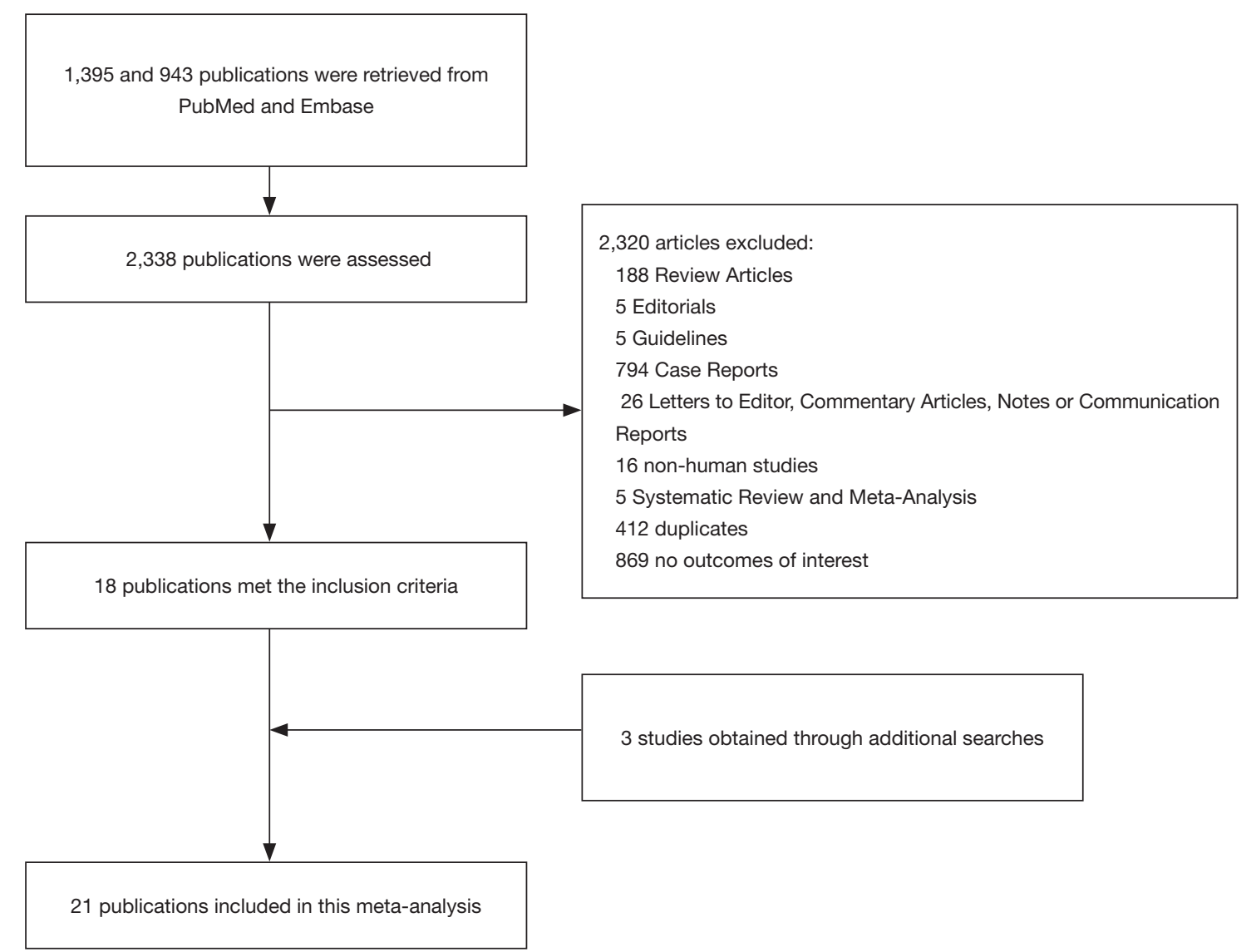

Figure 3 Flow diagram showing the study selection process for studies investigating association between survival and initial treatment for type A intramural hematoma (IMH).

which 2 studies showed significantly lower odds of mortality with the surgery-first approach. The meta-analysis of these studies showed that overall initial surgical management had a survival benefit over medical therapy alone (OR: 2.14; 95\% CI, 1.41-3.26; P=0.0004) (Figure 4). Five studies looked into the difference in short term all cause survival between initial medical management followed by timely surgery versus upfront surgery. None of the studies showed significant differences on its own, and meta-analysis of the studies did not favour either treatment approach (OR: 0.76; 95\% CI, 0.29-1.97; $\mathrm{P}=0.58$ ) (Figure S3). The results of sensitivity analysis by excluding one study at a time are shown in Figures $S 4, S 5$.

\section{Discussion}

Robbins et al. first reported on 13 patients with ascending aortic IMH with mortality rate of $66 \%$ (5). Subsequent studies have then shown medically managed type A IMH had mortality rates ranging from $30 \%$ to $80 \%$, these had guided the main-stream of treatment of acute type A IMH toward early surgery. Asian cohorts revealed lower mortality rates with medical treatment ranging from $0 \%$ to $8 \%$, and even showed complete resorption of IMH up to $67 \%$ on conservative treatment $(8-12)$. The rationale and emergence of medical therapy for type A IMH was founded on a few major considerations. Patients with type A IMH tend to be older with more medical comorbidities, and the natural history of type A IMH appears different from frank dissection in that there have been reports showing better survival on conservative treatment and lower incidences of malperfusion and acute aortic regurgitation (13). The reason behind the ethnic discrepancy is not known. However, the fact that patients can be initially managed conservatively with no excessive aortic-related complications is promising. While there should be no controversy in patients with acute life-threatening complications, in patients with uncomplicated type A IMH a more 


\begin{tabular}{|c|c|c|c|c|c|c|c|c|c|}
\hline Study or Subgroup & Initial MED Treatment & $\begin{array}{l}\text { nent } \\
\text { Total }\end{array}$ & $\begin{array}{r}\text { Initial SURG } \\
\text { Events }\end{array}$ & $\begin{array}{l}\text { ment } \\
\text { Total }\end{array}$ & Weight & $\begin{array}{c}\text { Odds Ratio } \\
\text { M-H, Fixed, } 95 \% \mathrm{Cl}\end{array}$ & \multicolumn{3}{|c|}{$\begin{array}{c}\text { Odds Ratio } \\
\text { M-H, Fixed, } 95 \% \mathrm{CI}\end{array}$} \\
\hline Choi 2014 & 7 & 47 & 1 & 14 & $4.1 \%$ & $2.27[0.26,20.26]$ & & & \\
\hline Estrera 2009 & 2 & 29 & 1 & 7 & $4.7 \%$ & $0.44[0.03,5.74]$ & & & \\
\hline Evangelista 2004 & 3 & 4 & 3 & 8 & $1.6 \%$ & $5.00[0.34,72.77]$ & & & \\
\hline Evangelista 2005 & 3 & 9 & 6 & 14 & $9.7 \%$ & $0.67[0.12,3.81]$ & & & \\
\hline Harris 1997 & 2 & 4 & 0 & 4 & $0.8 \%$ & $9.00[0.30,271.65]$ & & & \\
\hline Harris 2012 & 4 & 10 & 13 & 54 & $7.6 \%$ & $2.10[0.51,8.62]$ & & & \\
\hline Hata 2014 & 17 & 66 & 4 & 105 & $7.1 \%$ & $8.76[2.80,27.43]$ & & & \\
\hline Ho 2011 & 8 & 25 & 2 & 9 & $6.2 \%$ & $1.65[0.28,9.79]$ & & & \\
\hline Kitai 2009 & 9 & 50 & 1 & 16 & $3.9 \%$ & $3.29[0.38,28.24]$ & & & \\
\hline Lee 2014 & 3 & 44 & 1 & 17 & $4.2 \%$ & $1.17[0.11,12.10]$ & & & \\
\hline Moizumi 2002 & 1 & 24 & 1 & 11 & $4.1 \%$ & $0.43[0.02,7.66]$ & & & \\
\hline Moizumi 2004 & 7 & 30 & 5 & 11 & $17.4 \%$ & $0.37[0.09,1.57]$ & & & - \\
\hline Motoyoshi 2003 & 6 & 26 & 1 & 10 & $3.4 \%$ & $2.70[0.28,25.83]$ & & & \\
\hline Nienaber 2004 & 4 & 5 & 2 & 7 & $1.0 \%$ & $10.00[0.65,154.40]$ & & & \\
\hline Sandhu 2018 & 1 & 22 & 0 & 23 & $1.4 \%$ & $3.28[0.13,84.87]$ & & & \\
\hline Shimizu 2000 & 3 & 11 & 0 & 2 & $1.8 \%$ & $2.06[0.08,54.80]$ & & & \\
\hline Song 2001 & 1 & 18 & 1 & 6 & $4.4 \%$ & $0.29[0.02,5.60]$ & & & \\
\hline Song 2007 & $\begin{array}{l}1 \\
3\end{array}$ & $\begin{array}{l}10 \\
35\end{array}$ & $\begin{array}{l}1 \\
1\end{array}$ & 16 & $\begin{array}{l}4.410 \\
3.9 \%\end{array}$ & $1.41[0.13,14.67]$ & & & \\
\hline Song 2009 & 6 & 85 & 2 & 16 & $9.7 \%$ & $0.53[0.10,2.91]$ & & & \\
\hline Sueyoshi 1997 & 1 & 8 & 0 & 5 & $1.6 \%$ & $2.20[0.07,64.90]$ & & & \\
\hline won Kodolitsch 2003 & 6 & 11 & 2 & 27 & $1.6 \%$ & $15.00[2.32,96.96]$ & & & \\
\hline Total $(95 \% \mathrm{Cl})$ & & 563 & & 382 & $100.0 \%$ & $2.14[1.41,3.26]$ & & & \\
\hline Total events & 97 & & 47 & & & & & & \\
\hline $\begin{array}{l}\text { Heterogeneity. } \mathrm{Chi}^{2}= \\
\text { Test for overall effect }\end{array}$ & $\begin{array}{l}27.39, \mathrm{df}=2 \\
Z=3.57(\mathrm{P}=\end{array}$ & $0.121 ;$ & $1^{2}=27 \%$ & & & & 0.01 & $\begin{array}{c}1 \\
0.1 \\
\text { Favours [MED] }\end{array}$ & Favours [s \\
\hline
\end{tabular}

Figure 4 Forest plot demonstrating odds ratios for the relationship between survival in patients treated with initial medical and surgery.

conservative management is not irrational. Presuming there is absence of flow in the false lumen and no intimal tears, the likelihood of acute presentation of mal-perfusion or retrograde progressive dissection into the aortic root is not high. With this consideration, conservative management with tight blood pressure control appears adequate to tide the patient over in the acute phase for further organ optimization, repeat scans or planning for definitive extensive aortic procedures. Our cohort is one of the largest case series reported to date studying the relative merits of upfront surgery and the medical-first approach, and among the patients treated medically initially, $36 \%$ had resolution of IMH on blood pressure control alone.

All patients with cardiac tamponade, rupture or malperfusion were operated immediately. With increasing experience with aortic surgery, we have been more inclined to adopt the upfront surgery approach for good risk patients with uncomplicated type A IMH. So far, our emergency aortic operative mortality for type A IMH is zero. None of the 26 patients operated within 24 hours died from the surgery, and continued to survive to one year with no need for subsequent aortic intervention. One of the advantages of surgery over medical treatment is that successful repair spares the patient from a long high dependency unit stay and repetitive CT scans. It is worth mentioning that immobilization itself also bears risks of serious complications, especially in the elderly, such as infection, deep vein thrombosis/pulmonary embolism and general deconditioning. Despite our tendency to offer upfront surgery, a selected group of patients were still managed conservatively and the factors considered included presence of complicating comorbidities, thickness of IMH, presence of ULP/PAU in the arch or descending aorta suggesting retrograde $\mathrm{IMH}$, and availability of supporting staff and facilities. 39 patients with type A IMH were treated initially with anti-impulse therapy in a high dependency unit setting. These patients had a thinner IMH in the ascending aorta and PAUs were more readily identifiable in the arch or descending aorta. In this patient group, the 1 year all-cause survival was promising, with $94.9 \%$ surviving at 1 year. Interestingly, regardless of the initial strategy, the overall survival of type A IMH was excellent with a 1 year overall all cause survival of $96.9 \%$.

Another important perspective on management of acute type A IMH is that there is a possibility that some of these cases were actually retrograde dissections with thrombosed false lumen. In our analysis. $61.5 \%$ of patients who did not receive emergency operation had a PAU or ulcer-like projection in the arch or descending aorta on presenting scan. This suggests that type A IMH does not always equate classical type A dissection and can behave differently (14). This creates a clinical dilemma for the attending surgeon on whether to emergently proceed to a "palliative" ascending or hemiarch replacement, or to attempt a curative surgery 
such as a total arch replacement and elephant trunk procedure. From our findings, a reasonable approach would be to initially treat these patients conservatively followed by definitive "curative" treatment, as a model of delayedsurgical approach. If expertise is not readily available, initial medical treatment could be adopted with a view to transfer the patient to a more established aortic centre for a more extensive procedure. In our series, 35/65 (53.8\%) patients were initially admitted to a non-cardiac surgical centre and transferred to our unit for further management. From our data, for emergency procedures within 24 hours, $88 \%$ were ascending/hemiarch replacements, while for the medicalfirst approach group, the variety of procedure broadened, and the rate of ascending replacements was $50 \% .28 \%$ had a total arch replacement and elephant trunk procedure and $17 \%$ had a TEVAR, $5 \%$ of the cases had an open descending aortic replacement. Operative results were satisfactory in terms of 30-day survival, but it appears, by delaying surgery with the medical first approach, a more definitive surgical procedure could be performed with curative-intent especially in patients in which a definite PAU/ULP could be found in the arch or more distally. In our cohort, half of the $46.2 \%$ of patients who needed subsequent aortic interventions had arch or descending procedures done. For the 18 patients with medical therapy who had subsequent aortic intervention, only $2 / 18$ were done as emergency procedures, while most were electives. It should however be emphasized that it is difficult to accurately differentiate IMH from a thrombosed false lumen of a dissection clinically, and it may not be possible to confidently rule out the presence of focal, small intimal tears on computed tomography. Hence efforts should be directed to improve diagnostics of IMH, including the use of contrast echocardiography to stratify IMH patients at risk of complications

Pooling together the findings of 21 studies and 900 patients, the meta-analysis found that upfront surgery provided better odds for survival. The OR of 2.13 (1.403.25); $\mathrm{P}=0.0005$ was found in favour of emergency surgery in type A IMH in terms of survival. A meta-analysis in 2008 of 12 studies involving 328 patients, however, did not find differences in early mortality, and recommended individualized treatment (15). Our literature review was more contemporary, but we did not find high quality comparative trials. However, we found that Asian cohorts published more recently did not echo the findings of previous studies, Hata et al. (16) and Ho et al. (17) showed favourable survival with surgery in type A IMH. Hata et al. found medically treating patients with type A IMH resulted in hospital death rates up to $25.8 \%$, and for the survivors, $7.6 \%$ developed severe cardiorespiratory complications and $6 \%$ developed stroke during inpatient monitoring. The authors attributed this to bed rest management during initial blood pressure control, which increased risks of cardiorespiratory complications. In their series, there was no case of mortality post emergency surgery for patients with uncomplicated type A IMH. They were not able to identify risk factors that predicted complications in patients with uncomplicated type A IMH who were treated medically. Interestingly, for those who survived the hospital stay, 10-year survival in the medical group was not different from the surgical group. Ho et al. found a $32 \%$ hospital mortality rate for patients treated medically, and they attributed this mortality rate to the lack of optimal medical management with poor blood pressure control. It is worth noting that in their series, surgical mortality for type A IMH was $22 \%$, and this might be explained by the sicker nature of surgical patients. The lack of high-quality studies means any sweeping conclusion on management of type A IMH should be avoided, nonetheless a trend can be discerned. The management of type A IMH should be individualized with careful analysis of patient profile and imaging characteristics. Isolated series have found aortic size of $50 \mathrm{~mm}$ and thickness of IMH larger than $11 \mathrm{~mm}$ predicted complications and mortality (18-20). In our analysis, a $\mathrm{MAD} \geq 45 \mathrm{~mm}$ was predictive of need for future aortic intervention, but not emergent complications. In addition, MAD $<45 \mathrm{~mm}$ was predictive of spontaneous resolution of IMH. Our rate of emergency conversion from medical to surgery was low, perhaps indicating that we had made the right clinical choices on tailoring different management strategies to different patients. With a good aortic surgery program, one can argue that most type A IMH patients should be operated, given the low risk of mortality and morbidity. Nonetheless, for stable patients who have no aortic complications and a MAD $<45 \mathrm{~mm}$, if there is a possibility that the risk of an emergency surgery is considerably high or there is a view to perform a more curative procedure, a medical-first approach followed by timely surgery or CT surveillance could be considered as part of an individualized approach.

This study is retrospective, and we cannot discount the intrinsic bias and limitations of a data review. Accuracy of data collection and selection bias decrease the scientific value of the conclusion. Nonetheless, this cohort adds to the existing body of evidence that medical therapy is feasible in 
selected patients with type A IMH. The sample size is small, and control of confounders were not optimal. The outcome of interest is relatively short term, and longer follow up to 5 years is needed for a more comprehensive analysis of the merits and shortcomings of medical treatment. For the meta-analysis, this was a study-level meta-analysis and in contrast to data-level meta-analysis, the accuracy would be lower. The majority of included studies were of fair to low quality, and definitive differentiating data was lacking. Nonetheless our retrospective analysis and meta-analysis have shown that an individualized approach is feasible in the management of type A IMH, and that surgery is not the only approach.

\section{Conclusions}

Medical treatment of type A IMH in the acute setting is safe and feasible provided careful patient selection is performed. Conservatively managed patients should be offered high dependency unit care and close blood pressure monitoring. The rate of emergency conversion to surgery is low, and the 1 -year survival is promising. Advantages of an individualized approach allows better patient selection for surgery and optimization of patient comorbidities, as well as thorough planning for more definitive therapy. While surgery remains the gold standard for most patients with type A IMH, an individualized approach towards management of these patients should be adopted.

\section{Acknowledgments}

Funding: None.

\section{Footnote}

Conflicts of Interest: The authors have no conflicts of interest to declare.

Ethical Statement: The authors are accountable for all aspects of the work in ensuring that questions related to the accuracy or integrity of any part of the work are appropriately investigated and resolved. This cardiac surgical local registry was approved by the Hong Kong Hospital Authority and the Government of Hong Kong SAR to allow collection, analysis, reporting and outcome tracking of patient data since its introduction in 2007. No informed consents from patients were sought for this retrospective analysis as there were no identifiers in this manuscript that could disclose individual patient confidentiality.

Open Access Statement: This is an Open Access article distributed in accordance with the Creative Commons Attribution-NonCommercial-NoDerivs 4.0 International License (CC BY-NC-ND 4.0), which permits the noncommercial replication and distribution of the article with the strict proviso that no changes or edits are made and the original work is properly cited (including links to both the formal publication through the relevant DOI and the license). See: https://creativecommons.org/licenses/by-nc-nd/4.0/.

\section{References}

1. Yamada T, Tada S, Harada J. Aortic dissection without intimal rupture: diagnosis with MR imaging and CT. Radiology 1988;168:347-52.

2. Alomari IB, Hamirani YS, Madera G, et al. Aortic intramural hematoma and its complications. Circulation 2014;129:711-6.

3. Krukenberg E. Beitrage zur Frage des Aneurysma dissecans. Beitr Pathol Anat Allg Pathol 1920;67:329-51.

4. Harris KM, Braverman AC, Gutierrez FR, et al. Transesophageal echocardiographic and clinical features of aortic intramural hematoma. J Thorac Cardiovasc Surg 1997;114:619-26.

5. Robbins RC, McManus RP, Mitchell RS, et al. Management of patients with intramural hematoma of the thoracic aorta. Circulation 1993;88:II1-10.

6. von Kodolitsch Y, Csosz SK, Koschyk DH, et al. Intramural hematoma of the aorta: predictors of progression to dissection and rupture. Circulation 2003;107:1158-63.

7. Kitai T, Kaji S, Yamamuro A, et al. Clinical outcomes of medical therapy and timely operation in initially diagnosed type a aortic intramural hematoma: a 20-year experience. Circulation 2009;120:S292-8.

8. Song JK, Yim JH, Ahn JM, et al. Outcomes of patients with acute type a aortic intramural hematoma. Circulation 2009;120:2046-52.

9. Moizumi Y, Komatsu T, Motoyoshi N, et al. Clinical features and long-term outcome of type A and type B intramural hematoma of the aorta. J Thorac Cardiovasc Surg 2004;127:421-7.

10. Song JK, Kim HS, Song JM, et al. Outcomes of medically treated patients with aortic intramural hematoma. Am J Med 2002;113:181-7. 
11. Kaji S, Akasaka T, Horibata Y, et al. Long-term prognosis of patients with type a aortic intramural hematoma. Circulation 2002;106:I-248-52.

12. Choi YJ, Son JW, Lee SH, et al. Treatment patterns and their outcomes of acute aortic intramural hematoma in real world: multicenter registry for aortic intramural hematoma. BMC Cardiovascular Disorders 2014;14:103.

13. Evangelista A, Mukherjee D, Mehta RH, et al. for the International Registry of Aortic Dissection (IRAD) Investigators. Acute intramural hematoma of the aorta: a mystery in evolution. Circulation 2005;111:1063-70.

14. Song JK, Kang DH, Lim TH, et al. Different remodeling of descending thoracic aorta after acute event in aortic intramural hemorrhage versus aortic dissection. Am J Cardiol 1999;83:937-41.

15. Kan CB, Chang RY, Chang JP. Optimal initial treatment and clinical outcome of type A aortic intramural hematoma: a clinical review. Eur J Cardiothorac Surg 2008;33:1002-6.

Cite this article as: Chow SCY, Wong RHL, Lakhani I, Wong MV, Tse G, Yu PSY, Ho JYK, Fujikawa T, Underwood MJ. Management of acute type A intramural hematoma: upfront surgery or individualized approach? A retrospective analysis and meta-analysis. J Thorac Dis 2020;12(3):680-689. doi: 10.21037/ jtd.2019.12.109
16. Hata M, Hata H, Sezai A, et al. Optimal treatment strategy for type A acute aortic dis-section with intramural hematoma. J Thorac Cardiovasc Surg 2014;147:307-11.

17. Ho HH, Cheung CW, Man HJ, et al. Type A aortic intramural hematoma: clinical features and outcomes in Chinese patients. Clin Cardiol 2011;34:E1-5.

18. Evangelista A, Dominguez R, Sebastia C, et al. Prognostic value of clinical and morphologic findings in short-term evolution of aortic intramural haematoma: therapeutic implications. Eur Heart J 2004;25:81-7.

19. Song JM, Kim HS, Song JK, Usefulness of the initial noninvasive imaging study to predict the adverse outcomes in the medical treatment of acute type A aortic intramural hematoma. Circulation 2003;108:II324-8.

20. Kaji S, Nishigami K, Akasaka T, et al. Prediction of progression or regression of type A aortic intramural hematoma by computed tomography. Circulation 1999;100:II281-6. 

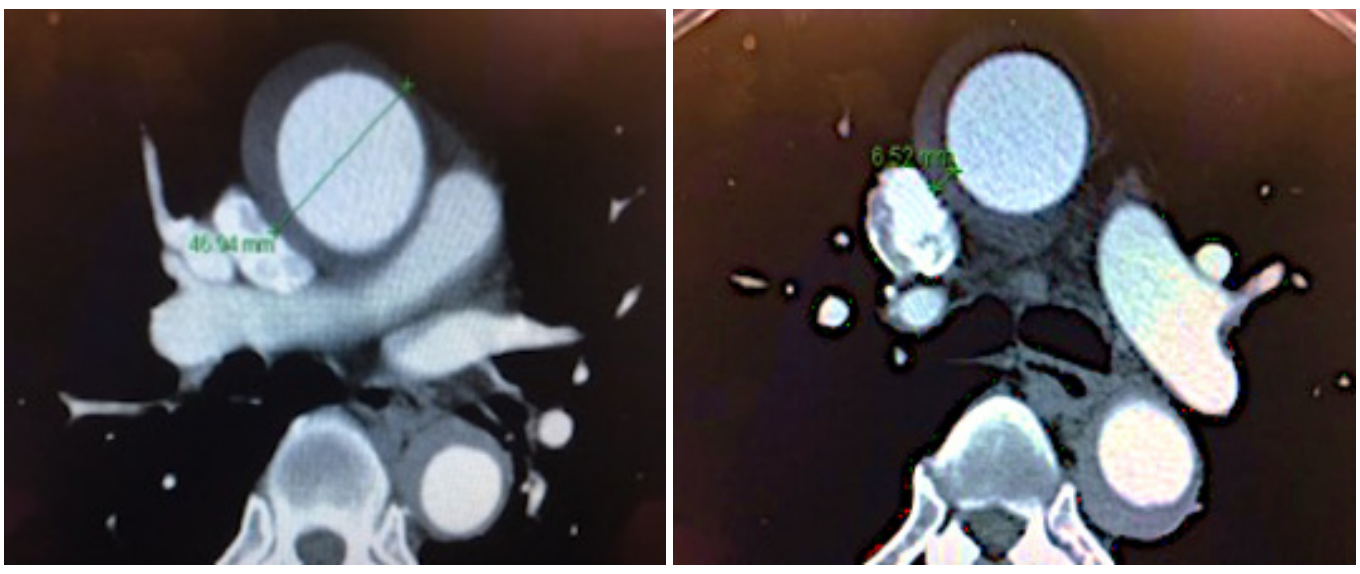

Figure S1 Measurement of maximal aortic dimension (MAD) and intramural hematoma thickness (IMH) on computed tomography scan: wall to wall diameter for MAD; thickness of IMH.

1 year all cause survival patients with type $\mathrm{A}$ IMH

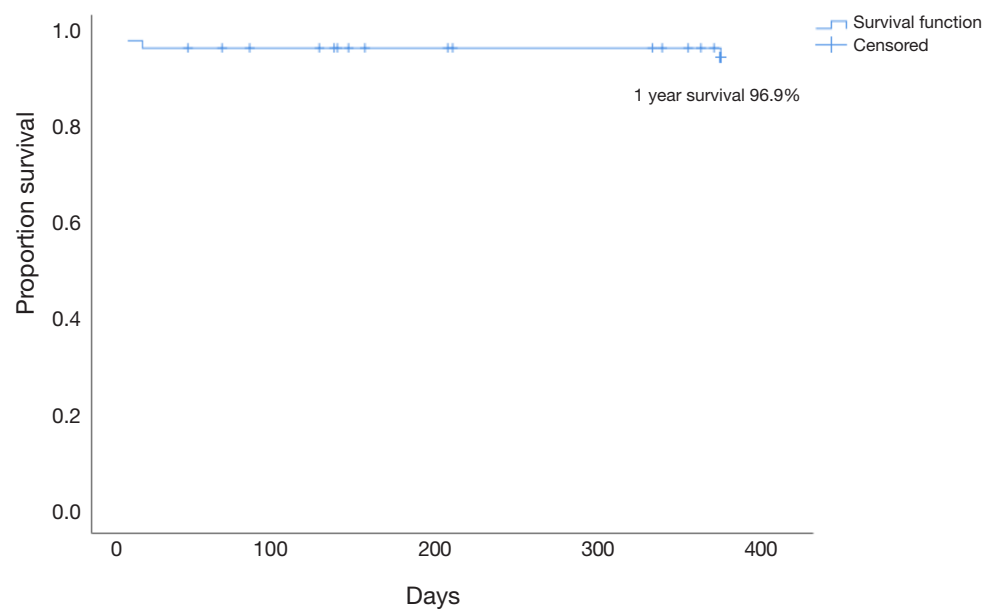

Figure S2 Kaplan Meier analysis showing overall 1 year all cause survival curve of all patients with acute type A IMH. 
Table S1 Types of aortic intervention

\begin{tabular}{lc}
\hline Intervention & Value \\
\hline Type of aortic intervention as emergency procedure $(\mathrm{n}=26)$ & $23(88 \%)$ \\
Hemiarch/ascending aortic replacement & $1(4 \%)$ \\
Hemiarch + AVR & $1(4 \%)$ \\
Bentall operation & $1(4 \%)$ \\
Hemiarch + femoral-femoral bypass & $9(50 \%)$ \\
Types of subsequent aortic intervention in patients with initial conservative treatment $(\mathrm{n}=18)$ & $5(28 \%)$ \\
Hemiarch/ascending aortic replacement & $3(17 \%)$ \\
Total arch replacement iÓ frozen/conventional elephant trunk & $1(5 \%)$ \\
TEVAR (all zone 2) & \\
Descending aortic replacement & \\
\hline
\end{tabular}

Table S2 Risk factor analysis for aortic intervention among patients treated conservatively initially

\begin{tabular}{lcc}
\hline \multirow{2}{*}{ Variable } & OR & P value \\
\cline { 2 - 3 } Age & 0.98 & 0.54 \\
Gender & 1.04 & 0.47 \\
Smoking & 0.30 & 0.75 \\
Hypertension & 1.04 & 0.49 \\
Diabetes & 0.80 & 0.61 \\
Max. aortic diameter & $1.41(95 \%$ Cl, 1.10-1.81) & 0.007 \\
IMH thickness & 1.13 & 0.11 \\
PAU & 0.51 & 0.53 \\
IMH thickness $<1 \mathrm{~cm}$ & 0.96 & 0.76 \\
MAD $\geq 50$ mm & 9.95 & 0.002 \\
MAD $\geq 45$ mm & $7.0(95 \%$ Cl, 1.7-29.4) & 0.007 \\
\hline
\end{tabular}


Table S3 Baseline characteristics and Newcastle Ottawa score of observational studies

\begin{tabular}{|c|c|c|c|c|c|c|c|}
\hline Study & Sample size (n) & No. of males & Age & SD & Study type & $\begin{array}{l}\text { Mean follow-up duration } \\
\text { (months) }\end{array}$ & $\begin{array}{l}\text { Newcastle-Ottawa Score of observational studies (P: }<5 \text { poor; F: } \\
\qquad 5-7 \text { fair; G: }>7 \text { good) }\end{array}$ \\
\hline Harris 1997 (4) & 19 & 7 & 70.9 & 10.0 & Retrospective & 72 & 6: $F$ \\
\hline Von Kodolitsch 2003 (6) & 38 & - & - & - & Prospective & 31 & $7: F$ \\
\hline Kitai 2009 (7) & 66 & 25 & 67.8 & 10.1 & Retrospective & 91 & $7: F$ \\
\hline Song 2009 (8) & 101 & 30 & 65 & 10 & Prospective & 37 & $7: F$ \\
\hline Moizumi 2004 (9) & 41 & - & - & - & Prospective & 52.9 & $6: F$ \\
\hline Choi 2014 (12) & 61 & 23 & 68 & 10 & Retrospective & 36 & $5: F$ \\
\hline Evangelista 2005 (13) & 23 & - & - & - & Retrospective & 19 & $7: F$ \\
\hline Hata 2014 (16) & 171 & 91 & 69.4 & 11.9 & Prospective & 62.6 & 6: F \\
\hline Ho 2011 (17) & 34 & 18 & 69.7 & 12.4 & Prospective & 30 & $6 ; F$ \\
\hline Evangelista 2004 (18) & 12 & - & - & - & Prospective & 3 & $6: F$ \\
\hline Song 2007 (21) & 51 & 15 & 66 & 11 & Retrospective & - & $5: F$ \\
\hline Estrera 2009 (22) & 36 & 24 & 63 & 13.5 & Retrospective & 42 (median) & $6: F$ \\
\hline Motoyoshi 2003 (23) & 36 & 20 & 68 & 9 & Prospective & 39 & $7: F$ \\
\hline Lee 2014 (24) & 61 & - & - & - & Prospective & 36 & $6: F$ \\
\hline Nienaber 1995 (25) & 12 & - & 52 & 10 & Prospective & 78 & $6: F$ \\
\hline Harris 2012 (26) & 64 & 37 & 69.6 & 9.6 & Prospective & 12 & $6: F$ \\
\hline Shimizu 2000 (27) & 13 & - & - & - & Retrospective & 37 & $6: F$ \\
\hline Song 2001 (28) & 24 & 5 & 67 & 10 & Retrospective & 17 & $5: F$ \\
\hline Sueyoshi 1997 (29) & 13 & - & - & - & Retrospective & 42 & $5: F$ \\
\hline
\end{tabular}

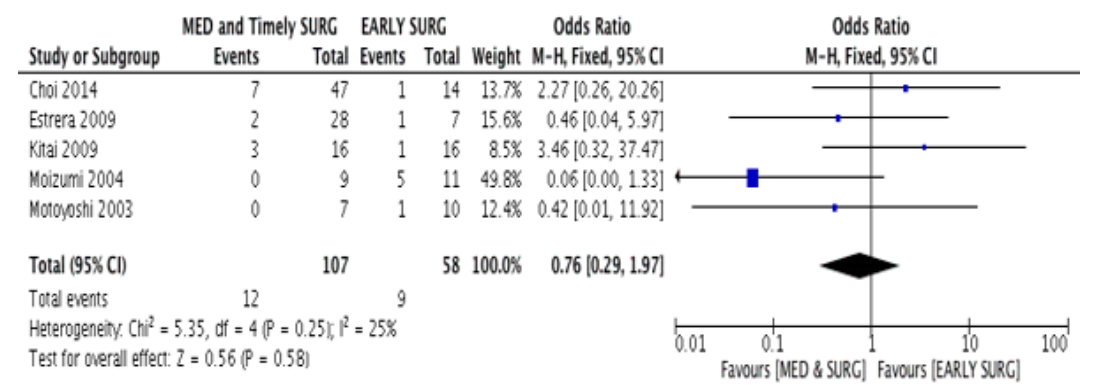

Figure S3 Forest plot showing odds ratio for the relationship between survival in patients treated with medical treatment followed by timely surgery \& early surgery. 


Study name
Choi 2014
Estrera 2009
Evangelista 2004
Evangelista 2005
Harris 1997
Harris 2012
Hata 2014
Ho 2011
Kitai 2009
Lee 2014
Moizumi 2002
Moizumi 2004
Motoyoshi 2003
Nienaber 2004
Shimizu 2000
Song 2001
Song 2007
Song 2009
Sueyoshi 1997
von Kodolitsch 2003

\begin{tabular}{lccrr}
\multicolumn{5}{c}{ Statistics with study removed } \\
Point & $\begin{array}{c}\text { Lower } \\
\text { limit }\end{array}$ & $\begin{array}{c}\text { Upper } \\
\text { limit }\end{array}$ & Z-Value & p-Value \\
1.961 & 1.238 & 3.106 & 2.869 & 0.004 \\
2.070 & 1.310 & 3.270 & 3.117 & 0.002 \\
1.921 & 1.217 & 3.033 & 2.801 & 0.005 \\
2.132 & 1.338 & 3.398 & 3.185 & 0.001 \\
1.921 & 1.220 & 3.025 & 2.817 & 0.005 \\
1.959 & 1.218 & 3.151 & 2.775 & 0.006 \\
1.500 & 0.919 & 2.447 & 1.621 & 0.105 \\
1.998 & 1.255 & 3.181 & 2.915 & 0.004 \\
1.928 & 1.216 & 3.055 & 2.794 & 0.005 \\
2.014 & 1.273 & 3.186 & 2.990 & 0.003 \\
2.050 & 1.300 & 3.234 & 3.087 & 0.002 \\
2.358 & 1.469 & 3.785 & 3.551 & 0.000 \\
1.948 & 1.230 & 3.084 & 2.845 & 0.004 \\
1.886 & 1.195 & 2.977 & 2.725 & 0.006 \\
1.972 & 1.252 & 3.106 & 2.928 & 0.003 \\
2.065 & 1.310 & 3.257 & 3.120 & 0.002 \\
1.999 & 1.264 & 3.163 & 2.960 & 0.003 \\
2.179 & 1.366 & 3.476 & 3.270 & 0.001 \\
1.970 & 1.251 & 3.102 & 2.925 & 0.003 \\
1.741 & 1.095 & 2.769 & 2.342 & 0.019 \\
1.973 & 1.258 & 3.095 & 2.959 & 0.003
\end{tabular}

Odds ratio $(95 \% \mathrm{Cl})$ with study removed

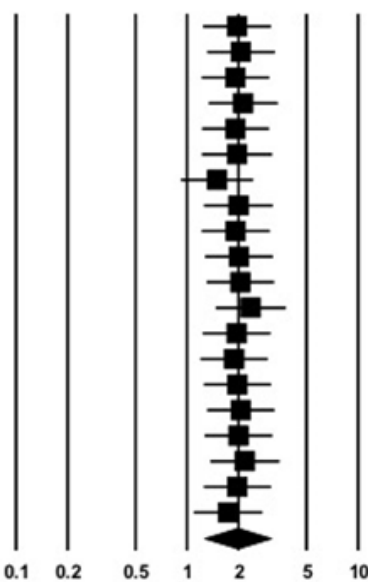

Figure S4 Sensitivity analyses by excluding one study at a time for the relationship between survival and initial medical therapy and upfront surgery.

\begin{tabular}{lcccrrr} 
Study name & \multicolumn{5}{c}{ Statistics with study removed } \\
& Point & $\begin{array}{c}\text { Lower } \\
\text { limit }\end{array}$ & $\begin{array}{c}\text { Upper } \\
\text { limit }\end{array}$ & Z-Value & p-Value \\
Choi 2014 & 0.595 & 0.150 & 2.365 & -0.737 & 0.461 \\
Estrera 2009 & 1.030 & 0.278 & 3.823 & 0.044 & 0.965 \\
Kitai 2009 & 0.564 & 0.148 & 2.151 & -0.839 & 0.402 \\
Moizumi 2004 & 1.365 & 0.386 & 4.824 & 0.484 & 0.629 \\
Motoyoshi 2003 & 0.964 & 0.278 & 3.350 & -0.057 & 0.954 \\
& 0.872 & 0.271 & 2.800 & -0.230 & 0.818
\end{tabular}

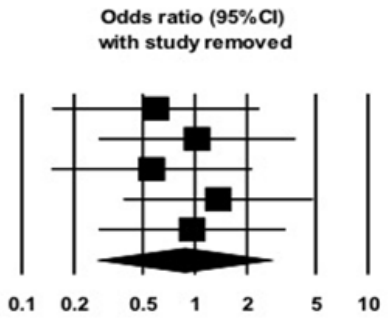

Figure S5 Sensitivity analysis by excluding one study at a time for the relationship between survival and timely surgery versus upfront surgery.

\section{References}

21. Song JK, Kang SJ, Song JM, et al. Factors associated with in-hospital mortality in patients with acute aortic syndrome involving the ascending aorta. Int J Cardiol 2007;115:14-8.

22. Estrera A, Miller C, Lee TY et al. Acute type A intramural hematoma: analysis of current management strategy. Circulation 2009;120:S287-91.

23. Motoyoshi N, Moizumi Y, Komatsu T, et al. Intramural hematoma and dissection involcing the ascending aorta: the clinical features and prognosis. Eur J Cardiothorac Surg 2003;24:237-42; discussion 242.

24. Lee CH, Park KH, Kwon TH, et al. Treatment patterns and it's outcomes of acute aortic intramural hematoma in real world: Daegu aortic hematoma registry data. European Heart Journal 2014;35:1196.
25. Nienaber CA, von Kodolitsch Y, Petersen B, et al. Intramural hemorrhage of the thoracic aorta: diagnostic and therapeutic implications. Circulation 1995;92:1465-72.

26. Harris KM, Braverman AC, Eagle KA, et al. Acute aortic intramural hematoma. An analysis from the international registry of acute aortic dissection. Circulation 2012;126:S91-6.

27. Shimizu H, Yoshino H, Udagawa H, et al. Prognosis of aortic intramural hemorrhage compared with classic aortic dissection. Am J Cardiol 2000;85:792-5, A10.

28. Song JK, Kim HS, Kang DH, et al. Different clinical features of aortic intramural hematoma versus dissection involving the ascending aorta. J Am Coll Cardiol 2001;37:1604-10.

29. Sueyoshi E, Matsuoka Y, Sakamoto I, et al. Fate of intramural hematoma of the aorta: CT evaluation. J Comput Assist Tomogr 1997;21:931-8. 